\title{
Influence of the Icelandic Low latitude on the frequency of Greenland tip jet events: Implications for Irminger Sea convection
}

\author{
F. Bakalian, ${ }^{1}$ S. Hameed, ${ }^{1}$ and R. Pickart ${ }^{2}$ \\ Received 10 July 2006; revised 29 September 2006; accepted 16 October 2006; published 26 April 2007.
}

[1] The occurrence of Greenland tip jet events has been reported as the dominant factor controlling the formation of intermediate water in the Irminger Sea. It has been suggested that the frequency of these events is correlated with the North Atlantic Oscillation. To examine this process in more detail, we separate the North Atlantic Oscillation into Icelandic Low and Azores High components and carry out a regression fit of the frequency of tip jet events between 1961 and 2005. Our findings suggest that the frequency of Greenland tip jet events is highly dependent on the latitude of the Icelandic Low and the 2-year time-lagged February Icelandic Low latitude, with $\mathrm{R}^{2}=0.48$. We find that the winds near the southern tip of Greenland are predominately westerly during years when the Iceland Low is located above $63^{\circ} \mathrm{N}$ latitude. These conditions also correspond to colder air temperatures in the Labrador and Irminger Seas, implying larger oceanic heat losses due to the Greenland tip jet events and hence stronger convective overturning in the Irminger Sea.

Citation: Bakalian, F., S. Hameed, and R. Pickart (2007), Influence of the Icelandic Low latitude on the frequency of Greenland tip jet events: Implications for Irminger Sea convection, J. Geophys. Res., 112, C04020, doi:10.1029/2006JC003807.

\section{Introduction}

[2] The Greenland tip jet has been suggested as a dominant factor in the formation of deep water in the Irminger Sea [Pickart et al., 2003]. Owing to the high relief of Greenland, these northwesterly winds descend on the eastern side of Greenland, accelerating in the process and transforming into narrow, low-level jets, drawing cold air over the Irminger Sea [Dörnbrack et al., 2004; Doyle and Shapiro, 1999; Pickart et al., 2003; Moore and Renfrew, 2005]. These brief, localized, intermittent and strongly seasonal winds were found to correspond to enhanced wind stress curl and heat loss during the winter season months, between December and March, within a narrowly confined region from $58^{\circ} \mathrm{N}$ to $62^{\circ} \mathrm{N}$ latitude and $36^{\circ} \mathrm{W}$ to $41^{\circ} \mathrm{W}$ longitude. The frequency of these tip jet events was found to range between 4 to 10 per winter, and was found to be positively correlated with North Atlantic Oscillation (NAO) index. Pickart et al. [2003] also suggested that the Jet events were influenced by the eastward motion of the NAO sea level pressure pattern. They reported that although the frequency of events did not change significantly in the winter of 1999 (when the NAO center of action was shifted to the east), the jet events were more moderate and hence less likely to drive convective overturning. Dickson [2003], on the other hand, suggested that the eastward displacement

\footnotetext{
${ }^{1}$ Marine Sciences Research Center, State University of New York at Stony Brook, Stony Brook, New York, USA.

${ }^{2}$ Woods Hole Oceanographic Institution, Woods Hole, Massachusetts, USA.

Copyright 2007 by the American Geophysical Union. 0148-0227/07/2006JC003807\$09.00
}

of the NAO pattern should increase the northwesterly airflow over the Irminger Sea.

[3] To better understand the driving forces controlling the frequency and onset of the Greenland tip jet events, we investigate here the relationship between the Jet events and the NAO. The concept that the displacements of the atmospheric centers of action can be used to explain changes in regional atmospheric circulation was first discussed by Rossby [1939]. Our calculations suggest that the atmospheric forcing responsible for this relationship comes primarily from the north-south displacements of the Icelandic Low, i.e., from the fluctuations of the Icelandic Low latitude (ILLA). We find that the wind patterns near Greenland during years of "extreme north" ILLA are favorable for the formation of tip jets. In addition, we find that there is a significant correlation between the frequency of tip jet events and the 2-year time-lagged ILLA. This suggests that alteration of the ocean circulation by the fluctuation of the Icelandic Low feeds back to the atmospheric conditions with a lag of nearly 2 years and may play a role in triggering tip jet events. Composites of air temperature have been constructed in conjunction with wind vector composites to provide more insight into the processes controlling the occurrence of tip jets.

\section{Method}

[4] A standard approach to characterizing the large-scale fluctuation in atmospheric pressure over the North Atlantic Ocean is to use the NAO index. The NAO index is based on measurements of the pressure difference between the Icelandic Low and Azores High at two fixed locations, Lisbon, Portugal and Stykkisholmur, Iceland. However, it is known 
that these two pressure systems have extended structures that migrate considerably and whose motions are not entirely coupled. As such, a better estimate of the influence of atmospheric pressure fluctuations on the Greenland tip jet events can be attained through a more quantitative assessment of the fluctuations in the pressures and the locations of these Centers of Action (COA). We consider here the variations of the Azores High and the Icelandic Low systems, separately. To model the pressures and locations of these COA, which vary considerably over spatial and temporal scales, we introduce "objective" indices for the pressure, latitude and longitude locations for both centers. By examining the monthly sea level pressure maps of the past 100 years, the latitude-longitude domains over which each of the pressure centers migrate were identified. Monthly sea level pressure (SLP) data were taken from the National Center for Atmospheric Research (NCAR) in calculating the COA indices [Trenberth and Paolino, 1980]. The spatial domains covered by the "objective" indices are: the Icelandic Low System $\left(40^{\circ} \mathrm{N}-75^{\circ} \mathrm{N}, 90^{\circ} \mathrm{W}-20^{\circ} \mathrm{E}\right)$ and the Azores High $\left(20^{\circ} \mathrm{N}-50^{\circ} \mathrm{N}, 70^{\circ} \mathrm{W}-10^{\circ} \mathrm{E}\right)$, as described by Hameed et al. [1995]. The pressure index is defined as an area-weighted pressure departure from a threshold value of the domain $(\mathrm{I}, \mathrm{J})$ :

$$
\mathrm{I}_{\mathrm{p}, \Delta \mathrm{t}}=\frac{\sum_{\mathrm{i}=1}^{\mathrm{I}} \sum_{\mathrm{j}=1}^{\mathrm{J}}\left(\mathrm{P}_{\mathrm{ij}, \Delta \mathrm{t}}-\mathrm{P}_{\mathrm{t}}\right) \cos \phi_{\mathrm{ij}}(-1)^{\mathrm{M}} \delta_{\mathrm{ij}, \Delta \mathrm{t}}}{\sum_{\mathrm{i}=1}^{\mathrm{I}} \sum_{\mathrm{j}=1}^{\mathrm{J}} \cos \phi_{\mathrm{ij}} \delta_{\mathrm{ij}, \Delta \mathrm{t}}}
$$

where $P_{i j, \Delta t}$ is the SLP value at grid point $(i, j)$ averaged over a time interval $\Delta \mathrm{t}$, in our case monthly SLP values are taken from NCAR, $P_{t}$ is the threshold SLP value $\left(P_{t}=1014 \mathrm{mb}\right.$ for Azores High and Icelandic Low), $\phi_{\mathrm{ij}}$ is the latitude of the grid point $(\mathrm{i}, \mathrm{j}), \mathrm{M}=0$ for the Azores High and 1 for the Icelandic Low. $\delta=1$ if $(-1)^{\mathrm{M}}\left(\mathrm{P}_{\mathrm{ij}, \Delta \mathrm{t}}-\mathrm{P}_{\mathrm{t}}\right)>0$ and $\delta=0$ if $(-1)^{\mathrm{M}}\left(\mathrm{P}_{\mathrm{ij}, \Delta \mathrm{t}}-\mathrm{P}_{\mathrm{t}}\right)<0$, this ensures that the pressure difference is due to an Azores High or Icelandic Low system. The intensity index is thus a measure of the anomaly of atmospheric mass over the sector $(\mathrm{I}, \mathrm{J})$.

[5] The Latitudinal index is defined as:

$$
\mathrm{I}_{\phi, \Delta \mathrm{t}}=\frac{\sum_{\mathrm{i}=1}^{\mathrm{I}} \sum_{\mathrm{j}=1}^{\mathrm{J}}\left(\mathrm{P}_{\mathrm{ij}, \Delta \mathrm{t}}-\mathrm{P}_{\mathrm{t}}\right) \phi_{\mathrm{ij}} \cos \phi_{\mathrm{ij}}(-1)^{\mathrm{M}} \delta_{\mathrm{ij}, \Delta \mathrm{t}}}{\sum_{\mathrm{i}=1}^{\mathrm{I}} \sum_{\mathrm{j}=1}^{\mathrm{J}}\left(\mathrm{P}_{\mathrm{ij}, \Delta \mathrm{t}}-\mathrm{P}_{\mathrm{t}}\right) \cos \phi_{\mathrm{ij}}(-1)^{\mathrm{M}} \delta_{\mathrm{ij}, \Delta \mathrm{t}}}
$$

and the longitudinal index $\mathrm{I}_{\lambda, \Delta \mathrm{t}}$ is defined in an analogous manner. These indexes have been calculated for the years 1899 to 2005. There are several advantages of separating the Centers of Action variables into latitude, longitude and pressure indexes. First, this approach assumes that each independent COA index can contribute directly to the tip jet events, allowing the relative contributions from each COA index on the frequency of Jet events to be computed. Second, this approach allows for the construction of regression models that explain a greater amount of the variance in Greenland tip jet events than the NAO index alone. Third, this approach reveals more insight into the atmosphere-ocean processes that control the frequency and onset of the Greenland tip jet events. The COA approach has been applied successfully to a range of regional climate problems such as explaining the variability of cloud cover over the western United States [Croke et al., 1999], the variations of zooplankton in the Gulf of Maine [Piontkovski and Hameed, 2002], the position of the Gulf Stream northwall [Hameed and Piontkovski, 2004] and the interannual variability of Saharan mineral dust transport over the Atlantic [Riemer et al., 2006].

\section{Calculations}

[6] We begin first by considering the relationship between the frequency of tip jet events and the NAO index. We use the December, January, February, and March (DJFM) NAO index values compiled by Hurrell at NCAR (http://www.cgd.ucar.edu/cas/jhurrell/indices.html). The tip jet data were obtained by extending the time series given by Pickart et al. [2003], using the same empirical orthogonal function approach, from 1961 through 2005. All data were averaged for the months of December through March. From this data, we obtained the following linear regression fit of Greenland tip jet events (GJE) to the NAO index:

$$
\mathrm{GJE}=6.408+0.888(\mathrm{NAO})
$$

$\mathrm{R}^{2}$ for the regression is 0.34 . Thus $34 \%$ of the variance in the GJE is explained by the variance in the NAO. By considering the two pressure centers independently, however, we will show that the amount of variance explained by the regression model will be significantly improved.

[7] Building on the result that the GJE is significantly correlated with the NAO, we now investigate the relative contributions of the Azores High (AH) and Icelandic Low (IL) to the GJE. We have correlated the pressure, latitude and longitude indices of the AH and IL with the GJE for the period 1961 to 2005 (Table 1). Correlations significant at the 95 percent level or more are shown in bold. The correlation coefficients are determined from the following expression:

$$
r_{y, x}=\frac{1}{N-1} \sum_{i}^{N}\left(x_{i}-\bar{x}\right)\left(y_{i}-\bar{y}\right)
$$

where $\mathrm{N}$ is the total number of samples, $\mathrm{x}_{\mathrm{i}}$ and $\mathrm{y}_{\mathrm{i}}$ are the independent and dependent variables, respectively, and $\bar{x}$ and $\bar{y}$ are the means of the independent and dependent variables, respectively. From the correlation coefficients, we find that the IL latitude, longitude, and pressure and the AH pressure and latitude are all potentially important variables influencing the frequency of GJE. We should comment however that the correlation coefficients calculated above reflect both direct contributions of the given COA index on GJE and indirect contributions from other COA indexes which interact with the given COA and GJE. Thus to isolate the effects of each COA index, we also computed the partial correlation coefficients for the four most significantly correlated COA indices and GJE (Table 2). The partial correlation coefficients 
Table 1. Correlation Coefficients of the Greenland Tip Jet Events Using DJFM Averages of Icelandic Low and Azores High Variables With Time Lags of 0 to 2 Years From 1961 to $2005^{\mathrm{a}}$

\begin{tabular}{lccc}
\hline \multicolumn{1}{c}{ Variable } & Present & 1 Year Lag & 2 Year Lag \\
\hline NAO index & $\mathbf{0 . 5 8}$ & 0.26 & 0.10 \\
IL pressure & $\mathbf{- 0 . 4 7}$ & -0.22 & -0.08 \\
IL latitude & $\mathbf{0 . 6 6}$ & 0.14 & $(0.28)$ \\
IL longitude & $\mathbf{0 . 3 2}$ & 0.18 & -0.19 \\
AH pressure & $\mathbf{0 . 4 0}$ & 0.14 & 0.13 \\
AH latitude & $\mathbf{0 . 4 3}$ & -0.10 & 0.22 \\
AH longitude & 0.17 & 0.10 & -0.01 \\
\hline
\end{tabular}

${ }^{a}$ Bold font indicates statistical significance at $95 \%$ confidence level or higher. Values enclosed in parentheses denote values close to but less than the $95 \%$ confidence level. DJFM is December, January, February, and March.

report the contribution from a given COA index on GJE while holding all other independent variables fixed. The partial correlation coefficients were calculated as follows:

$$
r_{a b c d e}=\frac{r_{a b d c}-r_{a e d c} r_{\text {bedc }}}{\sqrt{\left(1-r_{\text {aedc }}^{2}\right)\left(1-r_{\text {bedc }}^{2}\right)}}
$$

where the first two subscripts of $\mathrm{r}$, a and $\mathrm{b}$, represent the two variables (one independent, and one dependent) for which the partial coefficient is calculated and the subscripts c, d, and e represent those variables that are being held fixed. The partial coefficients for $r_{a b c d}$ and $r_{a b c}$ are calculated in an analogous manner. As shown in Table 2, only the IL latitude and GJE are correlated above the 95\% percent confidence level; when the IL latitude index is held fixed for other combinations of COA indexes and GJE, the contributions drop to nonsignificant levels. Thus the partial correlation coefficient, $r=0.49$, shows that the position of the IL latitude has a direct and significant effect on the frequency of GJE and is the dominant factor influencing the frequency of the Greenland Jets. On the basis of this information, we then constructed a linear regression model for IL latitude and GJE:

$$
\mathrm{GJE}=-40.61+0.79(\text { ILLA })
$$

$\mathrm{R}^{2}$ for the regression is 0.43 , a significant enhancement over the $\mathrm{NAO}$ value of $\mathrm{R}^{2}=0.34$. By separating the $\mathrm{NAO}$ into COA components, we have been able to isolate the main variable related to the frequency of Greenland Jet

Table 2. Partial Correlation Coefficients for Greenland Jet Events With Respect to Icelandic Low Pressure, Icelandic Low Latitude, Azores High Pressure, and Azores High Latitude ${ }^{a}$

\begin{tabular}{lc}
\hline \multicolumn{1}{c}{ Variables } & Partial Correlation Coefficients \\
\hline Jet events and IL latitude & $\mathbf{0 . 4 9}$ \\
Jet events and IL pressure & -0.10 \\
Jet events and AH latitude & -0.12 \\
Jet events and AH pressure & -0.26 \\
\hline \multicolumn{2}{c}{ a The four independent variables considered here are Icelandic Low (IL) } \\
latitude, IL pressure, Azores High (AH) latitude, and AH pressure. The \\
partial correlation coefficients between Greenland Jet events and a given \\
variable are computed by holding all other independent variables fixed. \\
Bold font indicates statistical significance at 95\% confidence level or \\
higher.
\end{tabular}

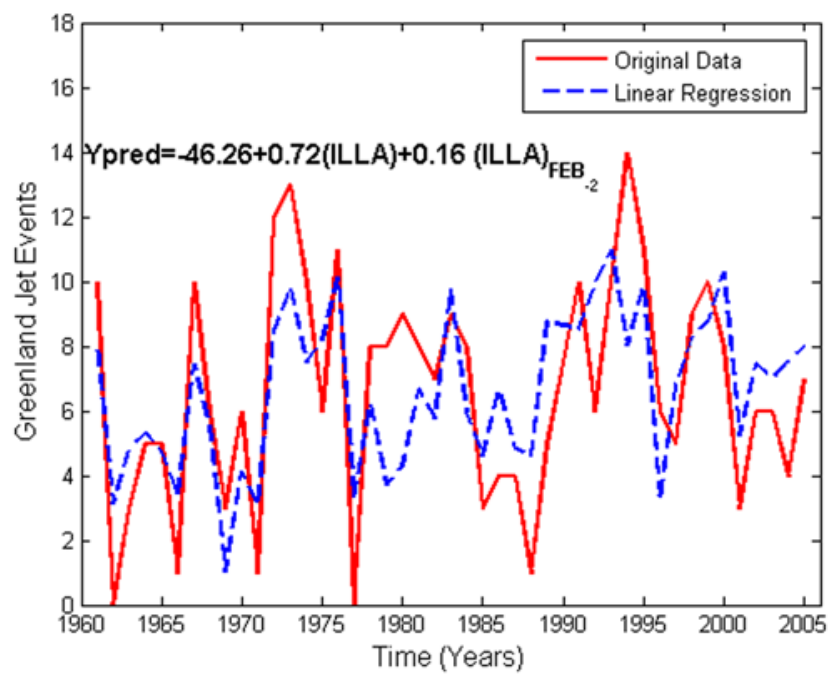

Figure 1. A comparison of the frequency of Greenland tip jet events and our modeled values based on a linear regression model for the years 1961 to 2005. The independent variables assumed in our regression model are the December, January, February, and March (DJFM) averaged Icelandic Low latitudes and the 2-year time-lagged February Icelandic Low latitudes. The variance in the Greenland tip jet events explained by our regression model is $\mathrm{R}^{2}=0.48$.

events and thus improve our regression model by $9 \%$ over the fit to the NAO data alone.

[8] To further improve the model we noticed that there is a rather high correlation for the 2-year time-lagged IL latitudes with GJE. Although the correlation coefficient was slightly less than the 95 percent significance level at $r=0.28$, the numbers suggested that there might be some underlying relation between these two variables that was being masked by averaging over DJFM. To examine this further, we computed the correlation coefficients for the Greenland Jet events with the 2-year time-lagged IL latitudes for the months of December, January, February, and March, respectively. We found that the correlation coefficient for the 2-year time-lagged February ILLA indexes was 0.38 , significantly above the $95 \%$ confidence level. We also determined the partial correlation coefficient for this COA index and found an $r$ value of 0.30 . Adding this variable to the regression model gives:

$$
\mathrm{GJE}=-46.26+0.72(\text { ILLA })+0.16(\text { ILLA })_{\mathrm{Feb}-2}
$$

$\mathrm{R}^{2}$ for this regression is 0.48 , a $5 \%$ improvement over the regression model using only ILLA and a 14\% improvement over the NAO indexes alone. A 2-year time lag suggests that atmosphere-ocean interactions may play an important role in triggering the onset of the Greenland Jet events, since atmospheric processes often dissipate over a short timescale of weeks to months. Further information on the specifics of our regression model is reported in Table 3. Beta is the standardized regression coefficient for each independent variable. If the dependent and independent variables are standardized to have zero mean and unit variance, the regression coefficients would be Beta. Thus 
Table 3. Statistical Analysis of the Linear Regression Model Suggested for Greenland Jet Events ${ }^{\mathrm{a}}$

\begin{tabular}{lccccc}
\hline \multicolumn{1}{c}{ Variables } & Beta & $\begin{array}{c}\text { Partial } \\
\text { Correlation } \\
\text { Coefficients }\end{array}$ & b Coefficient & t-test & P-Level \\
\hline IL latitude & 0.60 & 0.63 & 0.72 & 5.46 & $<0.001$ \\
IL latitude $\{\text { FEB }\}_{-2}$ & 0.23 & 0.30 & 0.16 & 2.14 & $<0.05$
\end{tabular}

${ }^{\mathrm{a}}$ The two independent variables are the DJFM averaged Icelandic Low latitude and the 2-year time-lagged February Icelandic Low latitudes. Beta is the regression coefficient when all the variables are standardized, normalized to zero mean and unit variance. The third column gives the partial correlation coefficients. The nonstandardized regression coefficients are reported in the fourth column in which the slope intercept, $\mathrm{b}_{0}$, is equal to -46.26 . The t-tests are computed for each $b$ coefficient, in which the null hypothesis is $\mathrm{H}_{0}: \mathrm{b}=0$.

the Beta coefficients compare the relative contribution of each independent variable in explaining the GJE. We find that the relationship is dominated by the ILLA by a factor of 2.61. This is also supported by the partial coefficients reported in Table 3. In the last column, we find that the regression coefficients of the ILLA and ILLA $_{\mathrm{Feb}-2}$ are statistically significant at the $\mathrm{P}<0.001$ and $\mathrm{P}<0.05$ levels, respectively. In Figure 1, we plot the GJE frequencies and the regression model predictions between 1961 and 2005. As shown, close agreement is found between our fit and the GJE.

[9] The data analysis described above suggests that IL latitudes and the 2-year time-lagged February IL latitudes affect the formation and onset of GJE. To further explore the relation between the GJE and IL latitudes, we now consider the mean wind velocity composites for 1976, 1989, 1993 and 2000 corresponding to those years in which the Icelandic Low latitude $\geq 63^{\circ} \mathrm{N}$ and composites for 1966, 1969, 1977 and 1996 corresponding to those years in which the Icelandic Low latitude $\leq 57^{\circ} \mathrm{N}$. The wind velocities were calculated for an isobaric surface of $700 \mathrm{mb}$, corresponding to an altitude of $\sim 3 \mathrm{~km}$, owing to the high relief of the Greenland continent. During the years of extreme north ILLA conditions, the average number of GJE is greater than 10 whereas during years of extreme south ILLA conditions the average number of GJE is less than 4. The composites are shown in Figure 2.

[10] As seen in Figure 2a, the winds near the southern tip of Greenland during extreme north latitude IL years are predominately westerly, with magnitudes ranging between $\sim 6$ and $\sim 8 \mathrm{~m} / \mathrm{s}$. There are two hypotheses that can be proposed to explain the origin of tip jet events. One possibility is that they could originate from cold air over the Greenland plateau that descends along mountain slopes, similar to katabatic winds, forming tip jet events on the southeastern boundary of Greenland. Another possibility is that the air parcels approach Greenland from the west and do not pass over the plateau, but rather skirt around it to the south, accelerating and descending in the process. The more storms that pass close to Greenland in the direction of Iceland during the winter season, the more tip jet events there will be during that season. There appears to be mounting evidence in favor of the latter explanation. In both scenarios, the westerly wind pattern would highly favor the onset of tip jet events; in the former scenario, the westerly winds would favor the onset of katabatic winds down the steep terrain of Greenland whereas in the latter, a larger percentage of the storm tracks would head toward Iceland during the winter season.

[11] In contrast, the winds near the southwestern tip of Greenland during extreme low-latitude IL years are predominately southerly, see Figure $2 b$. These winds, which are the strongest to the west of Greenland, tend to draw air toward the northwest central region of the Greenland continent. The average wind speeds are observed to increase from $\sim 4 \mathrm{~m} / \mathrm{s}$ at the southern tip of Greenland to $8 \mathrm{~m} / \mathrm{s}$ in the
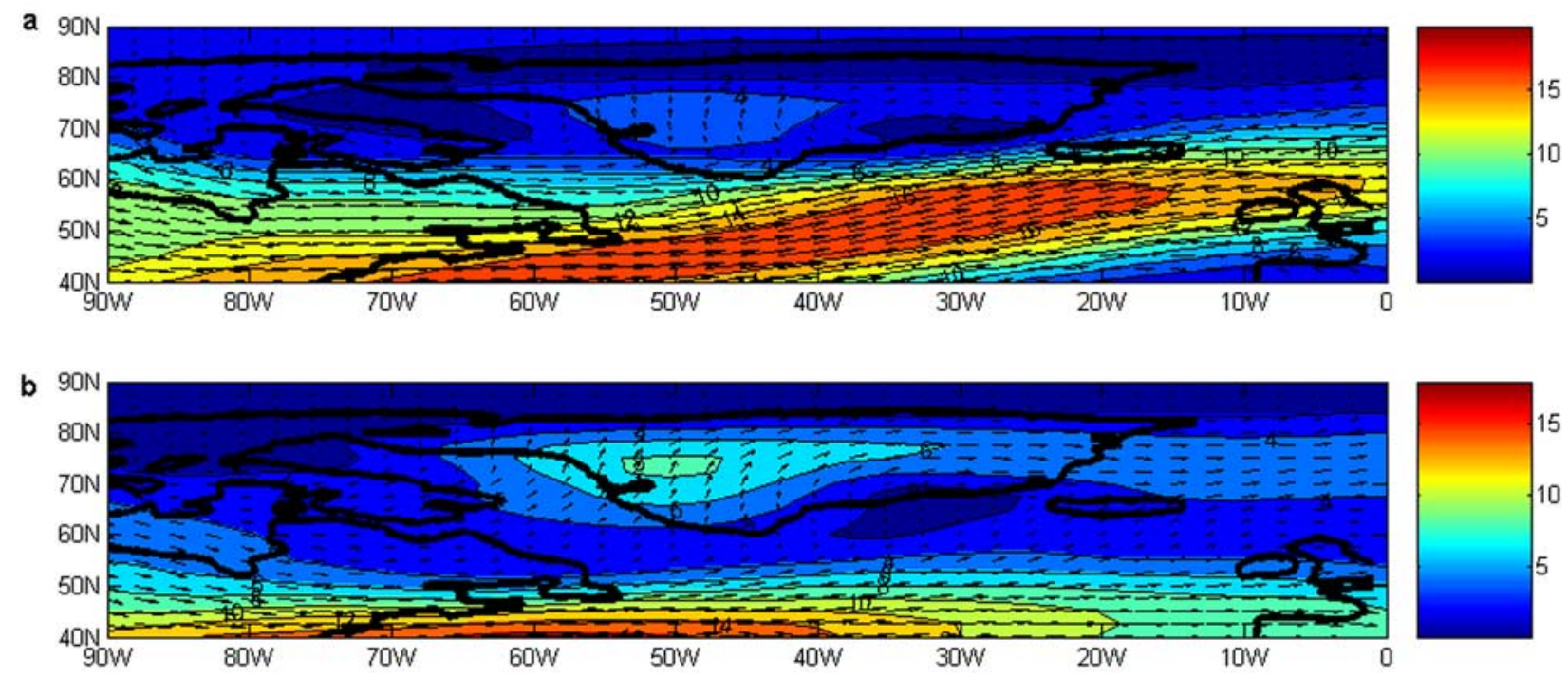

Figure 2. (a) Mean surface wind velocity composites for 1976, 1989, 1993, and 2000 corresponding to those years in which the Icelandic Low latitude $\geq 63^{\circ} \mathrm{N}$. The winds are predominately westerly near the southern tip of Greenland with a mean speed of $\sim 5$ m/s. (b) Same as Figure 2a but for 1966, 1969, 1977 , and 1996 corresponding to those years in which the Icelandic Low latitude $\leq 57^{\circ} \mathrm{N}$. Note that the winds are predominately southerly near the southern tip of Greenland with a mean speed of $\sim 3 \mathrm{~m} / \mathrm{s}$. 

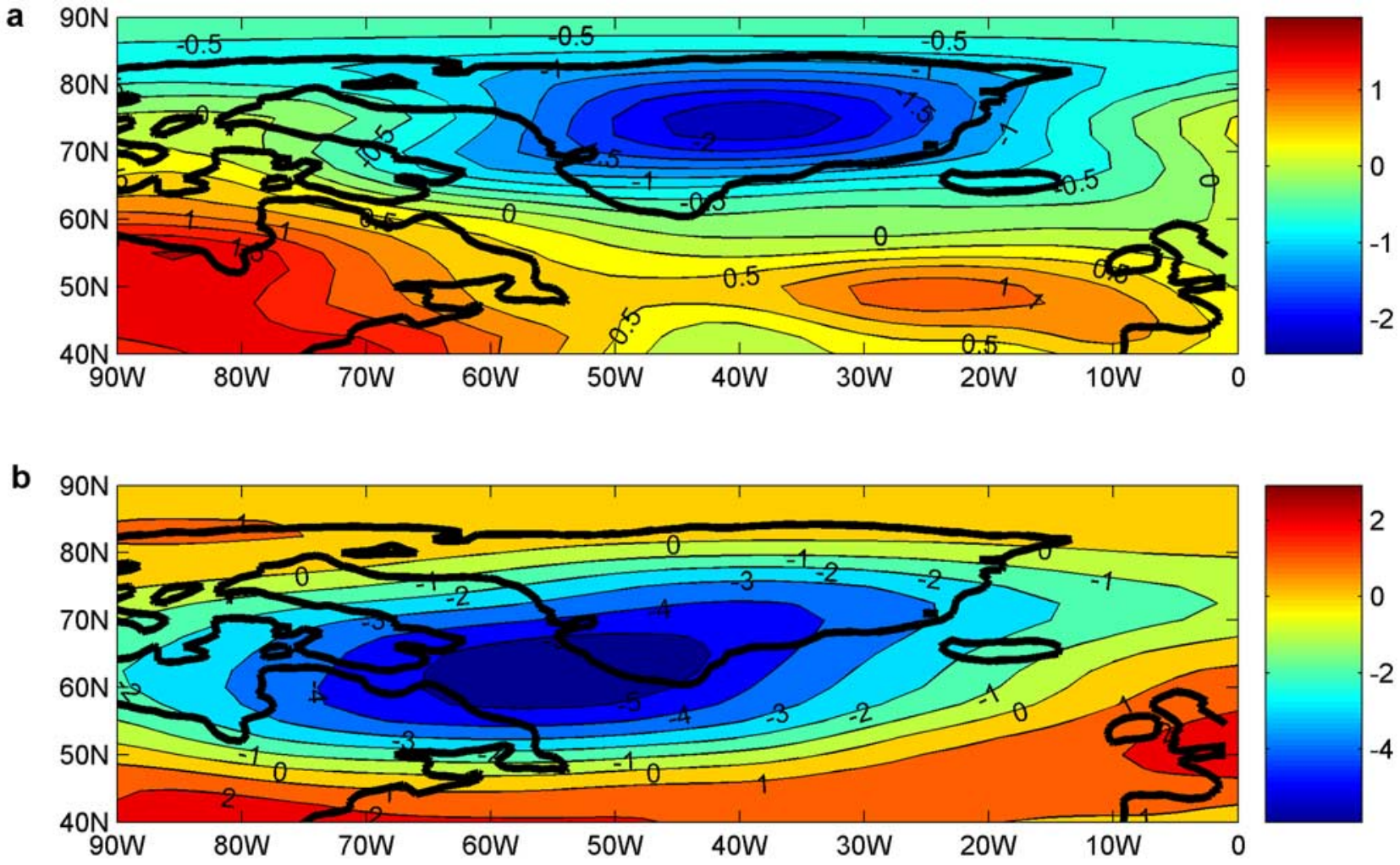

Figure 3. (a) Air temperature composites for the 4 years of "extreme north" Icelandic Low latitudes minus 4 years of "extreme south" Icelandic Low latitudes averaged for the months of September through November at an isobar pressure surface of $700 \mathrm{mb}$, corresponding to an altitude of $\sim 3 \mathrm{~km}$. (b) Same as Figure 3a but averaged for the months of December through March. As shown, the temperatures from December to March over the Labrador Sea and southwestern portions of Greenland are lower by as much as $-5^{\circ} \mathrm{C}$ during "extreme north" conditions as compared to "extreme south" conditions. This cold air mass forms over the central part of the Greenland continent and migrates southwestward during the winter months.

northwest central region of the Greenland continent. It is unlikely that this wind pattern is conducive to generating tip jet events. Thus these findings strongly suggest that the fluctuations in the latitude of the Icelandic Low is a key factor affecting the general wind circulation system at high latitudes near Greenland and the onset of Greenland Jet events.

[12] Air temperature composites for the years of extreme north ILLA minus extreme south ILLA at the isobaric surface of $700 \mathrm{mb}$ are shown in Figure 3. As seen in Figure 3a, there is a very large cold air anomaly that forms over the central portion of the Greenland continent in the months preceding the onset of GJE, September through November, during the years of extreme north ILLA as compared to extreme south ILLA. This cold air anomaly then moves southwestward with the advance of the winter months and resides over the Labrador Sea and southwestern portion of Greenland during the months of December through March. The temperature differences are observed to reach as much as $-5^{\circ} \mathrm{C}$ at the center of these cold air anomalies. The motion of this colder, heavier air mass during the years of extreme north ILLA as compared to extreme south ILLA, from central Greenland to the Labrador Sea and southwestern portion of Greenland, would favor the onset of tip jet events along the eastern (leeward) side of Greenland. This could be achieved through the generation of katabatic winds down the steep terrain of Greenland and/or increased storm activity in the Labrador Sea owing to the large air temperature gradient that develops between the Labrador Sea and its surrounding environments. Unlike deep convection in the Labrador Sea which is forced by the frigid polar air that blows off the Canadian land mass [Bumpke et al., 2002], our finding suggests that it is the displacement of the cold air mass that forms over the Greenland continent that triggers the Greenland Jet events and consequently the occurrence of deep convection in the Irminger Sea.

\section{Conclusions and Discussion}

[13] The results presented in this paper suggest that the frequency of Greenland Jet events (GJE) is significantly influenced by fluctuations in the latitude of the Icelandic Low. Our analysis indicates that the most significant contributors to the GJE are the ILLA and the 2-year timelagged February ILLA. We were able to explain $48 \%$ of the variance in the GJE using our regression model fits. As much as $43 \%$ of this variance could be explained by the present year ILLA alone. This statistical result is consistent with the wind circulation patterns and the air temperature composites observed over Greenland and the surrounding 
seas during years of extreme north and south IL latitudes. The findings of this research support the hypothesis that the Greenland tip jets, which are brief, localized, intermittent and strongly seasonal winds, are in fact influenced by fluctuations in the major atmospheric pressure systems of the Northern Hemisphere. Further research is required to understand how the seasonal-scale atmospheric conditions represented by the Icelandic Low constrain the synopticscale wind flows that constitute the individual jet events.

[14] The statistically significant correlation of the 2-year time-lagged February ILLA with the occurrence of GJE needs further evaluation. Although the mechanism by which the 2-year time-lagged February ILLA influences the occurrence of GJE is not well understood, it is possible that atmosphere-ocean feedback plays a role. One hypothesis is that the GJE and ILLA correlation is being reinforced by the slow response time of the ocean. Each winter a pattern of strong cyclonic windstress curl develops over the Irminger Sea due to the regional wind patterns (including the Greenland tip jet [see Moore and Renfrew, 2005]). It has been shown through numerical simulations that the communication between this seasonal atmospheric forcing and the circulation of the western North Atlantic subpolar gyre is achieved through baroclinic topographic Rossby waves which travel between $\sim 0.5$ and $1 \mathrm{~km} /$ day [Spall and Pickart, 2003]. As such, the ocean adjustment period should be on the order of $\sim 1$ to 2 years, roughly coinciding with our predicted 2-year time-lagged ILLA index. Hence the Irminger gyre should respond to changes in the Icelandic Low center of action on such a timescale, and the spinning up (down) of the gyre would result in more (less) warm, offshore water being advected close to the edge of Greenland. This in turn would alter the SST contrast with the cold Arctic origin water (or ice) on the shelf. This surface gradient plays a major role in the cyclogenesis of storms in the region [Tsukernik et al., 2007], so changes in the strength of the gradient could conceivably impact the number of storms that develop and hence the frequency of Greenland tip jet events. Although this scenario can explain the observed 2-year lag in terms of the memory of the ocean, the idea clearly needs to be investigated further in the framework of coupled atmospheric-oceanic modeling.

[15] Acknowledgments. R. Pickart gratefully acknowledges support by National Science Foundation grant OCE-0450658 for this research.

\section{References}

Bumpke, K., U. Karger, and K. Uhlig (2002), Measurements of turbulent fluxes of momentum and sensible heat over the Labrador Sea, J. Phys. Oceanogr., 32, 401-410.

Croke, M. S., R. D. Cess, and S. Hameed (1999), Regional cloud cover change associated with global climate change: Case studies for three regions of the United States, J. Clim., 12, 2128-2134.

Dickson, B. (2003), Stirring times in the Atlantic, Nature, 424, 141-142.

Dörnbrack, A., M. Weissmann, S. Rahm, R. Simmet, O. Reitebuch, R. Busen, D. L. R. Oberpfaffenhofen, and H. Olafsson (2004), Wind Lidar Observations in the Lee of Greenland, Extended Abstracts, 11th Conference on Mountain Meteorology and the Annual Mesoscale Alpine Programme (MAP Meeting), Bartlett, NH [CD-ROM P2.6], Am. Meteorol. Soc., Boston.

Doyle, J. D., and M. A. Shapiro (1999), Flow response to large-scale topography: The Greenland tip jet, Tellus, Ser. A, 51, 728-748.

Hameed, S., and S. Piontkovski (2004), The dominant influence of the Icelandic Low on the position of the Gulf Stream northwall, Geophys. Res. Lett., 31, L09303, doi:10.1029/2004GL019561.

Hameed, S., W. Shi, J. Boyle, and B. Santer (1995), Investigation of the centers of action in the North Atlantic and North Pacific in the ECHAM AMIP simulation, in Proceedings of the First International AMIP Scientific Conference, Monterey, California, WCRP-92, WMO/TD-732, pp. 221-226, World Clim. Res. Programme, Geneva.

Moore, G. W. K., and I. A. Renfrew (2005), Jets and barrier winds: A QuikSTAT climatology of high wind speed events around Greenland, J. Clim., 18, 3713-3725.

Pickart, R. S., M. A. Spall, M. H. Ribergaard, G. W. K. Moore, and R. F. Milliff (2003), Deep convection in the Irminger Sea forced by the Greenland tip jet, Nature, 424, 152-156.

Piontkovski, S., and S. Hameed (2002), Precursors of Copepod abundance in the Gulf of Maine in atmospheric centers of action and sea surface temperature, Global Atmos. Ocean System, 8, 283-291.

Riemer, R., O. M. Doherty, and S. Hameed (2006), On the variability of African dust transport across the Atlantic, Geophys. Res. Lett., 33, L13814, doi:10.1029/2006GL026163.

Rossby, C.-G. (1939), Relation between variations in the intensity of the zonal circulation of the atmosphere and the displacement of the semipermanent centers of actions, J. Mar. Res., 2, 38-55.

Spall, M. A., and R. S. Pickart (2003), Wind-driven recirculations and exchange in the Labrador and Irminger Seas, J. Phys. Ocean., 33, $1829-1845$.

Trenberth, K. E., and D. A. Paolino (1980), The Northern Hemisphere sea level pressure data set: Trends, errors, and discontinuities, Mon. Weather Rev., 108, 855-872.

Tsukernik, M., D. N. Kindig, and M. C. Serreze (2007), Characteristics of winter cyclone activity in the northern North Atlantic: Insights from observations and regional modeling, J. Geophys. Res., 112, D03101, doi:10.1029/2006JD007184.

F. M. Bakalian and S. Hameed, Marine Sciences Research Center, State University of New York at Stony Brook, Stony Brook, NY 11794-5000, USA. (shameed@notes. cc.sunysb.edu)

R. Pickart, Woods Hole Oceanographic Institution, M.S. 21, Woods Hole, MA 02543, USA. 